\title{
LA PRUEBA EN EL NUEVO CÓDIGO PROCESAL CIVIL
}

Por: Abog. Cesar Augusto Ramos Cáceres. Profesor Investigador, Instituto de Investigación Jurídica, Universidad Nacional Autónoma de Honduras.E-Mail: cesar_ramos63@yahoo.es

\section{Resumen}

La Prueba de acuerdo al nuevo procedimiento civil en Honduras constituye un ítem de alto valor a la luz constitucional y ejercicio de las garantías civiles, que generara procesos transparentes, que eviten la congestión judicial con el evidente letargo judicial al cual estamos acostumbrados.

Se pretende brindar al lector un análisis detallado, bajo los principios inspiradores de autores internacionales con expertis técnica en el área, exponiendo una a una las diferentes corrientes y sustentos doctrinales para las etapas del proceso civil en la cual destacan el principio de inmediación y la labor ardua que enfrentara el sistema judicial para reducir la mora y aumentar la eficiencia sin demeritar ninguna garantía constitu-cional del procesado y brindando en tiempo y forma una justicia pronta y segura.

La exposición cronológica del contenido del código pretende dar luz doctrinal a un proceso judicial innovador que pasara su prueba de fuego en los primeros 5 a 7 años de vigencia del nuevo instrumento jurídico como lo es el Código Procesal Civil.

Palabras Clave: Código Procesal Civil, prueba civil, inmediación, prueba electrónica, principios proceso civil.

\section{Abstract}

The test under the new civil procedure in Honduras was established as an item of high value in the constitutional light and exercise of civil guarantees which generate transparent processes to avoid judicial congestion with the apparent judicial lethargy we are accustomed to.

It is intended to provide the reader with a detailed analysis under the principles governing international authors who possess a technical expertise in the area, exposing one to one the different currents and doctrinal underpinnings for civil process steps which include the principle of immediacy and the arduous work faced by the judicial system to reduce the default and increase efficiency without discrediting any constitutional guarantee of the defendant and provided in a timely manner a secure prompt justice.

The chronological exhibition of the contents of the code, aims to give doctrinal light to an innovative judicial prosecution which it will have passed its acid test in the first 5 to 7 years of the new legal instrument such as the Civil Procedure Code.

Keywords: Code of Civil Procedure, civil trial, immediate, electronic evidence, civil procedure principles. 


\section{INTRODUCCIÓN}

El presente trabajo ha sido fundamentalmente elaborado, tomando como marco de referencia lo relacionado con la prueba en el Código Procesal Civil que se ha puesto en vigencia a partir del 1 de Noviembre del 2010.

El nuevo Código Procesal Civil del 2007, fue aprobado por el Congreso Nacional de la República, mediante Decreto Número 211-2006, entró en vigencia veinticuatro meses después de su publicación, es decir el 26 de mayo de 2009, quedando derogado el Código de Procedimientos Civiles de Honduras del 8 de febrero de 1906.

El punto de partida es el artículo número Uno (1) de la Constitución, donde establece "Honduras es un Estado de derecho, soberano, constituido como República libre, democrática e independiente para asegurar a sus habitantes el goce de la justicia, la libertad, la cultura y el bienestar económico y social" y lo que establece el artículo 90 cuando señala que "nadie puede ser juzgado sino por juez o tribunal competente con las formalidades, derechos y garantías que la ley establece".

En Honduras se regula La Prueba, en el Código Procesal Civil en los artículos del 228 al 349, donde se garantiza el respeto a los Derechos y Principios Cnstitucionales, de manera tal, que quede asegurada la probidad y la lealtad en la producción de la prueba.

Es evidente que la justicia se desarrolla como valor supremo. El valor supremo de la Justicia tiene hoy su fundamento en su reconocimiento democrático como garantía y consiguiente tutela judicial.- La justicia, se entiende como un logro a alcanzar para la plena realización del hombre y de la mujer, la plena eficacia de los derechos inviolables de carácter individual que la Constitución de la Republica reconoce.

Para que la justicia se logre es necesario que a la decisión del juzgador preceda una actividad adecuada, en la formulación de las pretensiones por medio de los Abogados y demostrar la realidad de las afirmaciones a través de alegaciones de parte y de pruebas, realizadas desde puntos de vista singulares y concretos que se ordenan a la resolución definitiva.

El Código Procesal Civil en vigencia se origina y sustenta en el anhelo de todos los hondureños de lograr una tutela judicial pronta y accesible, así como el derecho a un fallo justo por parte de los tribunales de justicia.

El derecho procesal civil, como derecho relativo a la decisión jurisdiccional de las controversias, de reafirmación del derecho y de pacificación social, ha de ser justo, imperativo y eficaz, en donde para obtener unos resultados adecuados, es necesaria 
una administración de justicia ágil, donde las personas que dirigen y resuelven el proceso, estén muy preparadas. Donde los letrados colaboren en la resolución de los procesos, y defiendan las pretensiones de sus clientes, bajo los principios de libertad e independencia.-

El Abogado cuando reflexiona, sobre el problema de su cliente, antes de plantearse el litigio, valora las distintas posibilidades, entre los que se encuentran la resolución extrajudicial del litigio, una vez que agota la posibilidad de resolver el conflicto al margen del Juzgado, se plantea la formulación del escrito de presentación de demanda, donde se inicia el camino para la prueba que debe de adjuntar, proponer, y como fin último convencer al Juez.-

Es por ello que el Código Procesal Civil, supone una innovación respecto al sistema procesal vigente, pretende aprovechar las instituciones y conceptos del antiguo Código, pero establece un nuevo modo de enjuiciar, entre las principales novedades que contiene el Código Procesal Civil, es la sustitución del actual proceso declarativo escrito por otro donde predomina la oralidad, sin abandonar en algunos casos la forma escrita.

El presente trabajo de análisis investigativo pretende contribuir con los estudiosos del derecho, estudiantes, catedráticos, operadores de justicia y procuradores judiciales, sobre los aspectos siguientes:

1. Conocer los medios de pruebas a aportar en la demanda.

2. Describir el desarrollo en el proceso adecuado

3. Procurar colaborar como debe practicarse la prueba.

Es necesario poner de manifiesto la derogación definitiva de la prueba de juramento y la prueba de confesión, que se sustituye por el interrogatorio de las partes La importancia de la prueba, está apoyada en la eficacia y la eficiencia de la Administración de Justicia.

Por otra parte, un proceso oral exige ante todo que el Juez que haya dirigido la audiencia probatoria sea el que dicte la resolución, bajo sanción de nulidad.- Esto puede suponer uno de los avances más importantes y de los cambios más profundos que en la justicia civil, cabe esperar de este Código, conforme enseña la práctica de los países más avanzados. 


\section{I.- LA PRUEBA: CONCEPTO, CARACTERES Y FINES}

\section{A.-CONCEPTO}

En toda la ciencia jurídica, se considera la definición de la prueba como complejo por su contenido.

La palabra prueba, tiene distintas acepciones, Guillermo Cabanellas de Torres, ${ }^{1}$ la define como la "demostración de la verdad de una afirmación, de la existencia de una cosa o de la realidad de un hecho." Es la persuasión o convencimiento que se origina en otro, y especialmente en el Juez o en quien haya de resolver sobre lo dudoso o discutido.-

Para el Profesor Prieto Castro, ${ }^{2}$ se considera prueba "actividad procesal que desarrollan las partes con el Tribunal para llevar al Juez a la convicción de la verdad de una afirmación o para fijarla a los efectos del proceso".

El Profesor Serra toma en consideración el hecho de que la prueba está en función de los escritos de alegaciones, por tanto, la finalidad de la prueba consiste en convencer al Juzgador sobre los hechos controvertidos y que fundamentan las pretensiones.

Algunos autores como Gimeno, ${ }^{3}$ consideran que "solo cabe hablar de prueba como la actividad encaminada a convencer al juez de la veracidad de unos hechos que se afirman existentes en la realidad".

En el Código Procesal Civil la palabra prueba tiene distintas acepciones, con la denominación "prueba", estamos designando varias cuestiones, por un lado la actividad que se realiza por las partes, (artículo 11 Código de Procedimientos Civiles), principio dispositivo (artículo 10); y por el Tribunal (artículo 12). Por otro lado podemos referirnos al resultado de dicha actividad o sea la valoración de la prueba, (artículo 13 CPC)

También nos podemos referir al medio a través del cual se consigue el resultado (artículo 251 CPC).

Es decir que la prueba tiene un fundamento previo, como es la demanda y la contestación a la demanda; así como la reconvención y la contestación a la reconvención, y un fundamento final, como es la sentencia.

A pesar de reconocer la riqueza semántica del vocablo prueba, De la Oliva, ${ }^{4}$ la define "como aquella actividad que desarrollan las partes con el tribunal para que

\footnotetext{
${ }^{1}$ Cabanellas, Guillermo de Torres. Diccionario enciclopédico de derecho usual ( 8 tomos, $25^{\star}$ edición,). Buenos Aires: Editorial Heliasta. 2003

${ }^{2}$ La valoración de la prueba penal, Escritos en homenaje al profesor Prieto Castro, T. II, Ed. National, Madrid, 1979

${ }^{3}$ Gimeno, Jacinto, "La prueba en el proceso civil" Universidad Abat Oliba C.E.U en Barcelona, España. 2007

${ }^{4}$ DE LA OLIVA SANTOS, ANDRÉS, y Otros, Comentarios a la Ley de Enjuiciamiento Civil, Civitas..Madrid, 2001, pág. 196-197.
} 
éste adquiera el convencimiento de la verdad o certeza de un hecho o afirmación fáctica o para fijarlos como cierto a los efectos de un proceso".-

Esta doctrina puede ser la que coincide, considero que tomando como hechos los alegados por la parte actora en su demanda, los hechos notorios, los no controvertidos, "La prueba es el convencimiento, entendido como resultado, al que llega el Juez después de haber estado presente en la práctica de todos los medios de prueba".

\section{B.- CARACTERES DE LA PRUEBA}

\section{1.- OBTENCIÓN DE LA VERDAD FORMAL O CERTEZA DEL HECHO.}

Autores consideran que hechos no afirmados al menos por una de las partes no existen para el juez, por tanto no puede salir a buscarlos; los hechos afirmados por ambas partes o afirmados por una o reconocidos por la otra, no pueden ser desconocidos, y la actividad probatoria es verificadora (contrasta la exactitud de las afirmaciones) NO ES INVESTIGADORA (hechos desconocidos que se buscan). Por tanto si el Juez estaba limitado en la búsqueda de los hechos, se admitió que la prueba no podía obtener "verdad verdadera", sino una verdad jurídica no basada en leyes de la lógica sino fundada en leyes jurídicas (Montero Aroca, 2006).

En esta verdad formal en análisis de nuestro Código, existen unos hechos alegados por la parte actora, que se admiten expresamente (por todas las partes asumen los hechos, Art.434.1 ro. CPC); o tácitamente (cuando se produce el silencio o la negativa a responder o la respuesta evasiva de la alegación, Art. 434.2do.), en cuyo caso el Tribunal puede considerar aceptación tácita de los hechos que le sean perjudiciales-.

\section{2.- ACTIVIDAD PROCESAL}

La prueba entendida como medio, modo o forma, tiene como fin el convencimiento del Juez "en que produzca certeza en el juez sobre a cuál de ellas asiste la razón y contribuyen a fundamentar las decisiones de fondo" (Art.228 CPC).

La dirección del proceso está a cargo del juez quien ejerce tal potestad de conformidad con lo dispuesto en la Constitución y en el Código Procesal Civil.

El Juez controla de oficio la concurrencia de todos los presupuestos procesales especificados por la ley, así como que no exista ningún acto causante de nulidad, antes de dictar sentencia.

El órgano jurisdiccional estará facultado para intervenir directamente en los casos previstos por el Código en aras de una decisión más justa, sin merma de los principios dispositivo y de aportación, que son privativos de las partes.

Sin perjuicio de la actuación de los interesados, el juez impulsará el proceso por sí 
mismo, siendo responsable de cualquier demora ocasionada por su negligencia. Están exceptuados del impulso de oficio los casos expresamente señalados en el Código. El órgano jurisdiccional debe resolver la cuestión litigiosa con arreglo a derecho, aunque no haya sido invocado por las partes o lo haya sido erróneamente, pero no puede alterar el petitorio ni fundar su decisión en hechos diversos de los que han sido alegados por las partes (Art, 12 CPC).-

En cuanto a la petición de prueba por las partes, cuando se contiene que son insuficientes, de modo que impidan una correcta formación de su convicción, podrá acordar la práctica de pruebas complementarias (Art. 229 CPC), pero si a pesar de ello la parte no considera necesario su practica no se puede sustituir los deberes y las cargas de las partes al respecto (ARt.229.3ro. CPC)

En cuanto a la valoración de la prueba, el órgano jurisdiccional, valorará la prueba de manera precisa y razonada, atendiendo siempre a las reglas de la sana crítica, del conocimiento, criterio humano y razonamiento lógico, salvo que el Código y otra ley establezcan una valoración concreta del resultado probatorio obtenido.

La valoración legal de la prueba sólo es admisible en el Interrogatorio de las partes, en la prueba documental y únicamente cuando una norma así lo indique expresamente o se deduzca de ella inequívocamente.

En todo caso el órgano jurisdiccional ha de exponer en su sentencia los razonamientos que lo condujeron a la apreciación y valoración de las pruebas para fundar su convencimiento, exista o no norma que le obligue, quedando prohibida la arbitrariedad (artículo 13 CPC).

En la prueba en todo caso, no se permite la arbitrariedad, es necesario tomar en consideración, además las reglas de la sana crítica, del conocimiento y criterio humano (artículo 245 CPC).

Además no se tomará en consideración la prueba prohibida cuando vulneren las garantías procesales establecidas en la Constitución de la República, Convenios Internacionales relativos a derechos humanos suscritos y ratificados por Honduras y en este Código, ni cuando para la obtención u origen de alguna prueba admitida se han vulnerado las garantías procesales fundamentales (artículo 237 CPC).

En cuanto a la prueba anticipada, no se otorgará valor alguno, si no se presenta la demanda en el plazo de un mes desde que ésta se practicó (artículo 247.2do. CPC).

\section{3.- ACTIVIDAD DE LAS PARTES}

La Constitución de Honduras no se ocupa de ordenar, distribuir y disponer cual deba ser la actividad del órgano judicial y de las partes en la realización y en el desarrollo de la estructura básica del proceso.

Este principio aparece en contraposición del principio de investigación de oficio. 


\section{C.- FINES DE LA PRUEBA}

En la doctrina se observa, que la prueba es un elemento ajeno al proceso, hasta tanto se manifiesta en la demanda como hecho del cual se derivan consecuencias jurídicas, desde cuyo momento nace el fin principal de la prueba, que es el convencimiento del Juez.

El convencimiento del Juez, está en algunas ocasiones reglado:

a) Cuando es un hecho no controvertido, y por tanto asumido por la parte demandada.

b) Cuando es un hecho notorio, y por tanto sin necesidad de alegarlo se reconoce.

El convencimiento del Juez, en otras ocasiones necesita de la práctica de pruebas para que se produzca, para lo cual el Código Procesal Civil, fija los deberes de las partes y terceros, respecto a la comparecencia en la audiencia preliminar y probatoria, así como las sanciones para el caso de no comparecer, así como la forma y método de practicar.

En el Código en referencia, se establece ese convencimiento al Juez o Tribunal, de la verdad o certeza de un hecho respecto a las afirmación que sean controvertidas (articulo 238 numeral 3 del CPC).

\section{II.- PRINCIPIOS INSPIRADORES DEL PROCESO EN MATERIA PROBATORIA}

\section{A.- ACCESO A LA JUSTICIA}

Este principio reflejado en el Articulo 14 numeral 1) del Pacto Internacional de Derechos Civiles y Políticos, así como en el Artículo 6 numeral 1) del Convenio Europeo de Derechos Humanos, se encuentra reconocido expresamente en el artículo 1 numeral 3ro. de nuestro Código Procesal Civil.

El principio es un complemento del derecho de petición reconocido en el artículo 1 numeral primero, garantizado en el artículo 80 de la Constitución de la República.Establece una prohibición en el artículo 1 ro. Numeral 2) cuando fija que "Se prohíbe el establecimiento de cualquier obstáculo de carácter social, político, económico, cultural o de otra índole, que impida o dificulte el acceso de cualesquier persona a la justicia".

Incluye una obligación para el órgano jurisdiccional, artículo 1ro, numeral 3ro, párrafo segundo como "El órgano jurisdiccional velará por el cumplimiento de éste artículo removiendo los impedimentos que se puedan producir y posibilitando el ejercicio de los mismos". 
Este derecho de los ciudadanos hondureños es para acceder a los Tribunales de Justicia, para obtener una tutela judicial.- Esta tutela judicial se debe de conceder por medio del debido proceso, previsto en el Articulo 3 del CPC cuando dice: "Las partes tienen derecho a que el proceso se desarrolle por los trámites previstos legalmente, a que se respeten los derechos procesales establecidos en la Constitución de la República y en las leyes ordinarias en condiciones de igualdad y sin dilaciones, y a que se dicte por órgano jurisdiccional competente, independiente e imparcial, una resolución de fondo justa y motivada".

El artículo número 1 del Código Procesal Civil emitido el 2007, establece el derecho de acceso a los Juzgados y Tribunales, y en concreto en su apartado primero indica "Toda persona tiene derecho a peticionar ante los juzgados y tribunales la tutela efectiva de sus derechos e intereses legítimos".

La función del proceso declarativo reside, precisamente, en averiguar si el actor tiene derecho a esa tutela en concreto y no a cualquier otra.

Es necesario tomar en consideración el hecho del comienzo de la petición con un desarrollo del derecho de acceso a la Justicia, como principio necesario para la obtención de la tutela judicial efectiva; con la consecuencia obligada de derecho a un proceso con todas las garantías, como son la audiencia, defensa, igualdad de las partes, regulados en el principio dispositivo de las partes, con un resultado de sentencia sobre el fondo, y un derecho a la ejecución.-

\section{B.- PRINCIPIO DISPOSITIVO}

Es el poder de las partes, respecto a la acción y al objeto del proceso.- Su fundamento, es necesario encontrarlo en la disponibilidad jurídica material de los derechos subjetivos en conflicto, como son las relaciones jurídico privadas.

El proceso civil solo puede iniciarse mediante acto procesal válido de parte, que sea consecuencia de la autonomía de la voluntad (artículo 9 CPC).

Salvo en los procesos no dispositivos relacionados con asuntos de familia con las particularidades que esta ley prevé, la parte que haya ejercido su derecho de acción determina con su pretensión el objeto del proceso; la parte que se oponga a la misma fija el objeto del debate con su resistencia. Lo mismo valdrá en caso de reconvención (artículo No. 10.1 CPC).

La resolución del órgano jurisdiccional que ponga fin al proceso ha de ser congruente con la petición del actor y con lo opuesto por el demandado, teniendo en cuenta las normas aplicables y las pruebas evacuadas.

Las partes pueden poner fin al proceso antes de que se dicte sentencia en cualquiera de las instancias, o en casación, en los términos fijados por este Código si el acto dispositivo está autorizado por las leyes (artículo 10.3 CPC).

Es necesario tomar en consideración este principio, basado en el poder de disposición 
sobre el derecho material, el poder de disposición sobre la pretensión y la vinculación del juez a la pretensión.

1) Sobre el derecho material.- Cuando el dominio de los derechos pertenece en exclusiva a los particulares, a nadie se le puede ejercitar su defensa ante los Tribunales, con la excepción de los procesos civiles de familia, filiación o incapacitación, donde el Ministerio Público es parte.

2) Sobre la pretensión.- Las partes no solo son dueñas de la acción o de la incoación del proceso, sino que lo son también de la pretensión y del proceso mismo, pudiendo disponer de él a través de toda una serie de actos con la fuerza de cosa juzgada (allanamiento, renuncia y transacción) o sin ella (desistimiento o caducidad).

3) Vinculación del Juez a la pretensión.- El juez tiene como obligación la congruencia de la sentencia con la pretensión del demandante, sin perjuicio de lo cual se deberá dar respuesta a todas las peticiones que se formulan en la demanda y en la contestación a la demanda.- Este principio del juez se encuentra en el artículo 208 numeral 1 ro. cuando indica "Las sentencias deben ser congruentes con las demandas y con las demás pretensiones de las partes, deducidas oportunamente en el pleito"

\section{C.- PRINCIPIO DE INMEDIACIÓN}

Está establecido en el Código Procesal Civil para garantizar el predominio de la oralidad en el proceso, es necesario que el Juez presencie y dirija la práctica de las pruebas salvo las excepciones establecidas (Art. 16 CPC) no pudiendo delegar o comisionar la práctica de un acto procesal oral, salvo excepciones ( Art. 16.2do. $\mathrm{CPC})$, caso contrario se expone a la nulidad de las actuaciones.

\section{D.- LA AUDIENCIA}

Es un principio general del Derecho que nadie puede ser condenado sin ser oído y vencido en juicio.- Este principio comporta que distintos tipos de procesos puedan desarrollarse y terminarse sin que intervenga la parte demandada.

La vulneración de este principio hace que exista un recurso denominado de audiencia al rebelde, donde por una serie de motivos, puede ser revisada la sentencia dictada en rebeldía (artículos 735 al 741). 


\section{E.- IGUALDAD}

Este principio, no refleja el hecho de que la parte demandante y la parte demandada, tengan los mismos derechos, sino que ambas partes, tienen la misma posibilidad, dentro de las asimetrías existentes en las distintas fases del proceso.

En la demanda la parte actora, tendrá que intentar probar su pretensión, mientras que la parte demandada, podrá probar hechos que modifiquen, o extingan la pretensión, en cuanto a la prueba de la carga (Art.238), se encuentra diferencia según se trate de parte actora y de parte demandada.

Es un principio de igualdad en la aplicación de la ley procesal.- Las partes son iguales en el proceso, teniendo los mismos derechos, obligaciones, cargas y oportunidades, en función de la posición procesal que ocupe. El órgano jurisdiccional está obligado a preservar la igualdad de las partes en el proceso y a evitar toda discriminación contra o entre ellas por razones de sexo, raza, religión, idioma o condición social, política, económica o de otra índole (Art. 5 CPC).

\section{F.- CONTRADICCIÓN}

Es necesario mencionar la existencia de dos posiciones enfrentadas, por un lado el actor que interpone su demanda y por otro el demandado que se opone a la misma. Es necesario mencionar el derecho de acceso al proceso, así como la titularidad de un status como parte dentro del mismo.

En el Acceso al proceso, el actor y el demandado tienen derechos de acción y de defensa, para acceder al proceso, así como a la prueba y la práctica de la misma, al desarrollo del juicio y a la adquisición del status como parte, para que de acuerdo con su legitimación puedan hacer valer su pretensión y defensa.

Todas las partes, considerando la dualidad de posiciones, tienen derecho a ser oídas por el juez antes de cualquier decisión que afecte directa o indirectamente a la resolución de fondo que deba tomarse, bien en la instancia, bien en los recursos, en cualquier proceso ordinario o especial, así como para la adopción de medidas cautelares y en la fase de ejecución, salvo que voluntariamente se coloquen en situación de rebeldía o que sea contraria la audiencia a la propia finalidad del acto, lo que deberá estar expresamente previsto(articulo 4 CPC).

\section{G.- CONCENTRACIÓN}

Con el fin de no alargar la celebración de las pruebas, se establece la utilización de la menor cantidad de audiencias posibles. Las audiencias que no finalicen a mediodía, continuarán esa misma tarde y si tampoco hubieren finalizado, el día o días siguientes. (Art. 17 CPC). 


\section{H.-PUBLICIDAD}

Es necesario tomar en consideración el contenido del artículo 131 del CPC (prohibición de secreto), el articulo 134 (publicidad de los actos procesales) y el articulo 116 (obtener información).

En cuanto a la prohibición de secreto, se refiere a las partes, si bien el apartado segundo de este artículo 131 se remite al Derecho de recibir y obtener información (art.116).

En cuanto a la publicidad de los actos procesales, se refleja en cuanto a la práctica de las pruebas en Sala de Audiencia, y en concreto se escuchará a las partes, antes de decidir, si el acto es a puerta cerrada. (art. 134. 3ro.).

\section{III.-OBJETO DE LA PRUEBA}

La prueba recaerá sobre alegaciones de los hechos que guarden relación con la tutela judicial que se pretenda obtener en el proceso, los usos y costumbres, y el derecho extranjero. (Art. 234 CPC)

Están exentos de prueba los hechos no controvertidos, por ser hechos admitidos (art.434. 2do. CPC), por ser hechos notorios (que se refieren como notoriedad absoluta y general, art. 235.2 CPC), sobre los que exista plena conformidad de las partes (art. 235.1 CPC).

El objeto de la prueba se encuentra formado por afirmaciones sobre hechos y no sobre normas jurídicas ya que estas son conocidas por el Juez salvo la excepción del Derecho extranjero.

El legislador establece "están exentos de prueba los hechos no controvertidos" (art. 235.1 del CPC), luego los que se deben de probar son los hechos controvertidos. Además las pruebas deben ser pertinentes, necesarias útiles y lícitas (art.236 CPC). Quedan excluidos de prueba los hechos admitidos por las partes, los hechos notorios de mutuo acuerdo, asumidos y los amparados por presunciones legales.

a) Hechos: (sucesos acaecidos en la realidad que tienen un efecto jurídico en el proceso), la prueba recaerá sobre hechos (art.234.1 CPC). En la doctrina se les conoce como afirmaciones de hechos o afirmaciones fácticas, y la certeza positiva o negativa de estas es lo que se persigue obtener con la actividad probatoria.

b) Hecho Notorio: Según el autor Calamandrei "son aquellos hechos cuyo conocimiento forma parte de la cultura normal propia de un determinado círculo social en el tiempo en que se produce la decisión", y añade "no es el conocimiento efectivo el que produce la notoriedad, sin la normalidad de este conocimiento en el tipo medio de hombre perteneciente a un determinado círculo social y por esto dotado de una cierta cultura". 
Es necesario distinguir el hecho notorio de la ciencia privada del Juez, pues el hecho notorio es conocido por una generalidad, mientras que la ciencia privada del Juez es individual.

En cuanto a la diferencia del hecho notorio y la máxima de experiencia es difícil de precisar, ya que el hecho notorio se refiere a hechos, la máxima de experiencia se refiere a conceptos, que ayudan al Juez en la apreciación de la prueba.

Algunos autores Ilegan a distinguir tres clases de hechos notorios:

1) Hecho notorio general o universalmente conocido más allá de las fronteras por pertenecer a la cultura universal.

2) El local o territorial de conocimiento reducido a un determinado país o localidad.

3) Judicial aquel que es percibido por el órgano jurisdiccional en el ejercicio de su potestad.

En España, el hecho notorio es necesario ser alegado, si bien no necesita ser probado. En Honduras no será necesario probar los hechos que gocen de notoriedad absoluta y general, pero como en España, es necesario ser alegado (artículo 235.2 CPC), por tanto estamos ante el supuesto de conocimiento general (indicado en el apartado "a)" anterior).

En el Código Procesal Civil, en la audiencia preliminar que es la fijación de los términos del debate "las partes podrán efectuar cuantas precisiones, aclaraciones y concreciones crean oportunas para establecer la más completa y precisa fijación de los términos del debate" (art. 459 CPC), e igualmente en la audiencia preliminar las partes de acuerdo con el juez o tribunal fijarán los hechos sobre los que existe disconformidad, así como los que resulten admitidos de acuerdo con el tribunal por ambas partes, que quedarán excluidos de prueba (art. 462 CPC).

La Costumbre, no constituye derecho sino en los casos en que la ley se remite a ella. La prueba de la costumbre no será necesaria si las partes están conformes en su existencia y contenido y sus normas no afectasen al orden público (art. 234.2 CPC). El Derecho Extranjero, podrá ser también objeto de prueba, deberá ser probado en los que respecta a su contenido y vigencia, pudiendo valerse el tribunal de cuantos medios de averiguación estime necesarios para su aplicación (art. 234.3․ CPC).

\section{A.- LOS CARACTERES DEL OBJETO DE LA PRUEBA}

1) Se toma como premisa la demanda donde el actor debe expresar los hechos en que se funde la petición, expuestos numeradamente en forma precisa, con orden de claridad (art. 424.5 CPC).

2) Se continua con la contestación a la demanda, donde el demandado "redactará en la forma prevenida para ésta" (art.434.1 CPC) y habrán de negarse o admitirse los hechos aducidos por el actor. El tribunal podrá considerar el silencio o las 
respuestas evasivas del demandado como aceptación tácita de los hechos que le sean perjudiciales (Art.434.2 CPC).

3) El Juez deberá de observar la existencia de disconformidad o duda en las afirmaciones de las partes, "las afirmaciones de hecho alegadas que sean controvertidas". (art.228 CPC).

4)El juez deberá admitir las pruebas que guarden relación con la tutela judicial que se pretenda obtener (art.234.1 CPC), una vez que se haya admitido hechos, o existan hechos notorios.

5) Es prueba prohibida cuando vulnera las garantías procesales, establecidas en la Constitución de la República, en los Convenios Internacionales relativos a derechos humanos suscritos y ratificados por Honduras y en este Código.

6) Es prueba ilícita cuando alguna parte entendiera que en la obtención u origen de alguna prueba admitida se han vulnerado las garantías procesales fundamentales, habrá de alegarlo de inmediato, con traslado, en su caso, a las demás partes. Igualmente de oficio podrá el Tribunal resolver en la audiencia probatoria en los procesos ordinarios; y antes de empezar la audiencia en los procesos abreviados. Se resolverá por auto.

7) Son impertinentes las pruebas que no guardan relación con lo que sea objeto del proceso.

8) Son improcedentes las pruebas no necesarias.

9) Son inútiles las pruebas que no esclarecen los hechos controvertidos.

\section{IV.- PROCESO PROBATORIO}

\section{A.- GENERALIDADES}

\section{1.- El Derecho a la Defensa}

Es el derecho que se concede a las partes para que puedan alegar y probar. Las partes podrán formular la demanda del proceso monitorio o pedir directamente por sí mismas al juez o tribunal el beneficio de asistencia jurídica gratuita así como la adopción de medidas urgentes de protección de sus derechos e intereses legítimos previamente a la interposición de la demanda (artículo 80 CPC).

Es aconsejable la intervención de profesional del derecho, salvo que la Ley disponga lo contrario que es el supuesto anteriormente indicado. Conforme indica el artículo 79 del CPC.-

\section{2.- Los Fundamentos de Derecho}

Es el conocimiento de la norma jurídica, por parte del Juez, incluida dentro de las facultades procesales.- "El órgano jurisdiccional debe resolver la cuestión 
litigiosa con arreglo a derecho aunque no haya sido invocado por las partes o lo haya sido erróneamente, pero no puede alterar el petitorio ni fundar su decisión en hechos diversos de los que han sido alegados por las partes" (artículo 12.5 CPC).

En concreto en el contenido formal de las sentencias, se expresarán en párrafos separados y numerados, los puntos de derecho fijados por las partes y de las cuestiones controvertidas, dando las razones y fundamentos legales del fallo que haya de dictarse, con expresión concreta de las normas jurídicas aplicables al caso (artículo 200.2.c) CPC).

El Juez tiene que tener conocimiento del Derecho vigente de su país, lo que no le excluye del conocimiento del derecho histórico de su país, y de la posibilidad que tiene de averiguar respecto al Derecho extranjero para su aplicación (artículo 234.3 CPC).

\section{B.- PROPOSICIÓN DE LA PRUEBA}

Según Montero Aroca, "es el acto por el que se precisa que medios de prueba desea practicar en el proceso", y en qué momento presentarla. Es un acto oral de postulación ajustado al principio de aportación de parte en el que el actor, en primer lugar y luego el demandado, tratan de acreditar sus pretensiones.

En este extremo, es obligatorio plantear la cuestión de la necesidad de la prueba.

En principio cuando se lee el artículo 239 "siendo necesaria la práctica de la prueba", es decir que el legislador ya supone la existencia de una serie de procesos, donde no se necesitará la prueba.

En la práctica se observa algunos supuestos, cuando se llega a la audiencia preliminar (bien por terminación anormal del proceso; el art. 447 considera que se puede sistematizar la finalización anormal del proceso en;

1. Actos unilaterales de las partes

a) Intraprocesales

i. Del demandante: la renuncia y el desistimiento

ii. Del demandado: allanamiento

b) Extraprocesales: Carencia de objeto y satisfacción extraprocesal

2. Actos Bilaterales

a) Transacción

b) Desistimiento

El legislador de Honduras considera estas situaciones como "Terminación del proceso sin sentencia contradictoria" (artículo 481 CPC). 


\section{C.- DURACION DEL PROCESO}

Lo que las partes hayan aceptado no se tendrá que someter a prueba, si parcialmente se prueba, entonces lo que falte que probar si se someterá a prueba.- Se fija el objeto de la prueba, sobre hechos en los que existe disconformidad, así como los hechos admitidos por ambas partes que quedan excluidos de prueba, en ese sentido de ahí resultará la duración del proceso (art. 462 CPC).

Si el proceso queda reducido, o sea si hubiese conformidad sobre todos los hechos, las partes conclu-irán poniéndole fin a la audiencia preliminar abriéndose el plazo para oír sentencia (art. $464.1^{\circ} \mathrm{CPC}$ ).

Cuando el Tribunal considere que las pruebas propuestas por las partes pudieran resultar insuficientes para el esclarecimiento de los hechos controvertidos lo pondrá de manifiesto a las partes indicando el hecho o hechos que, a su juicio, podrían verse afectados por la insuficiencia probatoria (artículo 229.2 en relación artículo 239.6 del CPC).

El Tribunal debe de escuchar a las partes sobre la deficiencia o insuficiencia de las pruebas, sin que sustituya la iniciativa probatoria de las partes ni sustituya los deberes y cargas de las mismas (art.229.3 en relación art. 230.1 CPC).

Cuando la prueba sea insuficiente para probar los hechos, el Juez instará a las partes a efecto que puedan completar o modificar sus proposiciones de prueba (art.239.6 párrafo último)

\section{D.- ADMISION DE LA PRUEBA}

Es la resolución que dicta el Tribunal, por medio de la cual se ordena la práctica de la prueba propuesta por las partes.

En contraposición existe la denegación de la prueba, pero en el Código Procesal Civil, se encuentra reconocido como la inadmisión de prueba (art.236 CPC).

La necesidad de la prueba se presenta cuando existan hechos controvertidos, ya que si el hecho se encuentra admitido por la parte contraria, la prueba debe de inadmitirse pues no es una facultad del Juez, sino un mandato legal (art.235.1 CPC).

La pertinencia es basada en el hecho de guardar relación con lo que es objeto del proceso.- En contraposición a esta pertinencia, aparece la impertinencia, como las pruebas que no guardan relación con el objeto del proceso (art.236.2 CPC).

La inutilidad de la prueba está basada en que los aspectos no pueden contribuir a esclarecer los hechos controvertidos (art.236.3 CPC).

Es necesario indicar que también existe la ilicitud como ahora explicaremos, pero está basada en la inadmisión de cualquier prueba que vulnere la ley.

La ilicitud viene como consecuencia de que en la obtención u origen de alguna prueba admitida se ha vulnerado las garantías procesales fundamentales (art.237.2 CPC) (ejemplo grabación conversación privada, sin conocimiento). 
En contraposición a esta ilicitud está la prueba ilícita, que vulneran las garantías procesales establecidas en la Constitución de la República, en los Convenios Internacionales relativos a derechos humanos suscritos y ratificados por Honduras y en este Código (artículo 237.1 CPC).

Cuando se formula la petición de prueba en la demanda, no puede ser admitida la prueba, hasta tanto no contesta la parte demandada, tomando en consideración si el hecho esta o no controvertido, si estamos ante un hecho notorio, asumido por la parte demandada, por tanto en relación con la petición de la prueba propuesta, no debe resolver el Tribunal, hasta que no se produzca la contestación de la demanda. Cuando se formula la petición de prueba en la contestación a la demanda, se debe resolver en la audiencia preliminar, tomando en consideración lo señalado en los artículo 444 al 465 del CPC.

La admisión de un medio de prueba no es recurrible (art. 240.3 CPC).

La denegación del recibimiento del pleito a prueba o la inadmisión de un medio de prueba es recurrible en reposición oralmente (una parte pone de manifiesto la infracción legal y una suscita explicación de las razones del recurrente art.694 CPC), y se resolverá en el acto, si se deniega el recurso de reposición se debe formular protesta al efecto de hacer valer sus derechos en el recurso de apelación contra la sentencia definitiva, en la doctrina se denomina apelación deferida (que puede o no interponerse, depende de la sentencia que se obtenga) (art.240.2 CPC).

La existencia de un "hecho nuevo o de una noticia nueva", se puede probar, pero el Tribunal puede rechazar mediante auto, la alegación de un hecho acaecido con posterioridad; si observase ánimo velatorio o mala fe procesal podrá imponer una multa (Art.241.3 CPC).

\section{E.- HECHOS NUEVOS}

Esto se presenta cuando se produce un suceso relevante para la fijación de la causa de pedir o para la concreción de los términos del debate, y se presenta:

A. Con posterioridad al momento en que se formulan alegaciones (demanda o contestación a la demanda).

B. Acontecido antes pero conocidos por las partes con posterioridad.

En ambos casos se pueden proponer la prueba de que estimen valerse las partes (art. 460 del CPC).

El auto que se dicte por el Tribunal admitiendo o denegando el hecho nuevo, no es susceptible de recurso (art.460.3 CPC).

Cuando el Tribunal considera que se trata de un hecho nuevo, en primer lugar deberá de conceder traslado para que conteste la parte contraria en un plazo de 5 días 
(Art.431.2 $2^{\circ}$ CPC).

Una vez que contesta la parte contraria, sin reconocer como cierto el hecho alegado, o deja transcurrir el plazo concedido, el Juez dicta auto por escrito, donde resuelve SI ES UN HECHO NUEVO, y por tanto se debe proponer la prueba pertinente y útil, (art.241.1 CPC) o SI NO ES UN HECHO NUEVO, acaecido con posterioridad o se evidencia que el hecho se pudo alegar en la demanda o contestación a la demanda, si se declara que NO ES UN HECHO NUEVO, se puede imponer una multa (art. 241. numeral 2) y 3) del CPC).

Cuando se considere que es un hecho nuevo, por su particularidad, se ordenará la admisión de documentos hasta el momento de comenzar el plazo para dictar sentencia (art.287.5 CPC).

\section{F.-ANTICIPACION DE LA PRUEBA}

El autor Montero Aroca, dice que consiste en la práctica de cualquier medio de prueba en un momento anterior al proceso, cuando exista temor fundado respecto a las personas o por el estado de las cosas.

Antes de iniciar cualquier proceso, el futuro demandante podrá solicitar la práctica de algún acto de prueba, cuando se dieran razones de urgencia o existiera temor fundado, de que, por causa de las personas o por el estado de las cosas, dichos actos no puedan realizarse en el momento procesal ordinario (art.246 CPC).

\section{G.- LAS MEDIDAS DE ASEGURAMIENTO}

Existen medidas de aseguramiento con el fin de evitar que por conductas humanas (previstas) o acontecimientos naturales (caso fortuito o fuerza mayor), se pueda destruir o alterar objetos materiales o estado de cosas (linderos, servidumbres).

Las medidas no especifican las que pueden adaptarse ya que indica por un lado las que permitan conservar cosas o situaciones o hacer constar fehacientemente su realidad y características; si bien también podrán dirigirse mandatos de hacer o no hacer, incurriendo en responsabilidad penal quien los infrinja.

El Juez puede adoptar otra distinta siempre que cumpla la misma finalidad y cause menores perjuicios a las partes o a terceros.

Los requisitos son que sea posible, pertinente y útil al tiempo de presentar la solicitud y haya motivos para temer que pueda resultar imposible (art.250.1 CPC).

El que pretenda incoarlo podrá pedir al tribunal que adopta las medidas de aseguramiento que resulten adecuadas para evitar que por conductas humanas o acontecimientos naturales, se puedan destruir o alterar objetos materiales o estados de cosas y resulte imposible en su momento practicar una prueba relevante o carezca de sentido proponerla (art.249.1 CPC).

Pierde toda la eficacia y no puede ser utilizada en el proceso, si la demanda no se interpone en el plazo de un mes, salvo que se acredite fuerza mayor u otra causa de 
análoga entidad (art.250.2 CPC).

\section{V.- MEDIOS DE PRUEBA}

Son los instrumentos de los que se valen las partes o el propio juez, para hacer posible la apreciación judicial de dicho objeto.

La incorporación de las fuentes de prueba al proceso se realiza a través de los medios probatorios.

Si bien su mención aparece en el Código Procesal Civil, se puede mencionar que no estamos ante un numerus clausus de pruebas ya que el inciso $2^{\circ}$ del artículo 251 establece que "cuando exista una fuente de prueba que deba incorporarse al proceso civil y ninguno de los medios de prueba indicados anterior-mente sea idóneo para ello, el Tribunal, a instancia de parte, adaptara la prueba a los medios de prueba anteriores, de manera que se pueda lograr la finalidad que se pretende y lo admitirá para su práctica, que se ejecutará y valorará conforme a las normas generales". Son medios de prueba admisibles en el proceso civil los siguientes:

A. Interrogatorio de las partes

B. Pruebas Documentales:

1. Documentos públicos

2. Documentos privados

C. Medios técnicos de reproducción del sonido y de la imagen, e instrumentos técnicos que permitan archivar y conocer o reproducir palabras, datos, cifras y operaciones matemáticas Ilevadas a cabo con fines contables o de otra clase

D. Testifical

E. Peritaje

F. Reconocimiento judicial

\section{A.- INTERROGATORIO DE LAS PARTES}

En la doctrina se considera una prueba libre o de libre valoración, se establece en el Código Procesal Civil, como una declaración de las partes (terceros designados por las partes), sobre hechos relevantes de los que tiene noticia, sean personales o no. Es un medio de prueba, que se desarrolla bajo los principios de inmediación (Juez y las partes litigantes, sus abogado y representantes, (art.16 CPC), concentración (en la misma audiencia ambas art. 4 CPC), oralidad (la formulación de las preguntas, las respuestas, la admisión o inadmisión de la pregunta art. 15 del CPC).

Los Sujetos pueden ser:

\section{Personas Físicas}

Son ciudadanos todos los hondureños mayores de 18 años, se puede conceder la emancipación voluntaria a los 18 años (art.264 Código Civil) si bien la mayoría de edad es a los 21 años. 
Se puede conceder legalmente por habilitación de edad (art.269 Código Civil). Cuando se trata de una persona mayor de 21 años tiene todos sus derechos. Cuando se trata de una persona emancipada se debe de acreditar el instrumento público, siendo necesaria la inscrip-ción en el Registro Civil (Art.264.3 CC). Cuando se trata de una persona habilitada de edad, se debe de acreditar la resolución judicial, que lo establece (Art.270.2 CC).

\section{Personas jurídicas}

Son el Estado, las corporaciones, asociaciones, y fundaciones de interés público, reconocidas por la ley (La personalidad de éstas empieza en el instante mismo en que, con arreglo a derecho, hubiesen quedado válidamente constituidas), mientras que las Asociaciones de interés particular, sean civiles, mercantiles o industriales a los que la ley conceda personalidad propia, independiente de la de cada uno de los asociados (artículo 56 del Código Civil ), se tomará en consideración que comparecerán los que tengan representación o los que legalmente los representan (art.62 CPC).

\section{Quienes intervienen en el proceso:}

1. La parte contraria (demandante o demandada) y son las partes quienes deben de contestar, se admite la posibilidad de que un colitigante proponga el interrogatorio de los demás colitigantes, siempre y cuando exista oposición o conflicto de intereses entre ambos.

2. La parte que tiene la misma posición que el solicitante (demandante o demandado), pero en este caso se establece que exista oposición o conflicto de intereses (Art. 23.2 ${ }^{\circ}$ CPC).

3. Tercera persona ajena a los litigantes, es la llamada en la doctrina como extraordinaria, donde el litigante, asume la declaración de un tercero, siendo el tercero, quien declara sobre hechos que conoce de una forma personal, si bien está trabajando a favor de uno de los litigantes.

\section{B.- PRUEBA DOCUMENTAL}

Se encuentra basada en el medio que soporta la prueba que desarrolla, como es el documento.

En la doctrina, según Montero Aroca, se considera el proceso civil, como el reino del Documento.

Los principios de esta prueba, son el principio dispositivo donde las partes pretenden convencer al Juez de sus pretensiones (art.10 CPC), con el principio de aportación de parte (art.11 CPC).

\section{1.- Tipos de Documentos}

Los documentos son considerados en los artículos 269 y 270 del Código Procesal Civil. 
Es documento todo objeto de naturaleza corpórea o real en el que consta por escrito una declara-ción de voluntad de una persona o varias o la expresión de una idea, pensamiento, conocimiento o experiencia (art.269.2 CPC). Los documentos pueden ser :

a.- Documentos públicos, según el artículo 270.2 son los autorizados por un funcionario judicial, por un notario o por un funcionario público competente, siempre que se cumplan las solemnidades requeridas por la ley.

b.- Documentos Privados, son todos aquellos que no son públicos. La protocolización, la legalización o certificación de un documento privado no lo convierte en público (art.270.3 CPC)

c.- El documento electrónico es el redactado en soporte electrónico que incorpora datos que estén firmados electrónicamente.

\section{El documento electrónico será soporte de:}

c.1.- Documentos públicos, por estar firmados electrónicamente por funcionarios que tengan legalmente atribuida la facultad de dar fe pública, judicial, notarial o administrativa, siempre que actúen en el ámbito de sus competencias con los requisitos exigidos por la ley en cada caso.

c.2.- Documentos expedidos y firmados electrónicamente por funcionarios o empleados públicos en el ejercicio de sus funciones públicas, conforme a su legislación específica.

\section{c.3.- Documentos Privados}

Los documentos tendrán el valor y la eficacia jurídica que corresponda a su respetiva naturaleza, de conformidad con la legislación que les resulte aplicable.

El soporte en que se hallen los datos firmados electrónicamente será admisible como prueba do-cumental en juicio.

\section{a.- Documentos públicos}

Estos documentos se mencionan en el artículo 271 del Código Procesal Civil.

La denominación de instrumentos en el Código Civil, deja paso a la de documentos públicos en el Código Procesal Civil.

Se pueden presentar por original, testimonio, copia o certificación fehaciente o si, habiendo sido aportado por copia simple, no se hubiere impugnado su autenticidad (art. 272 CPC).

La fuerza probatoria, indicada en el artículo 1499 Código Civil (hoy derogado) queda subsumida en el contenido del artículo 273 del Código Procesal Civil donde refleja cuando hacen prueba plena, aun contra tercero; y en concreto en materia de usura los 
Juzgados o Tribunales resolverán en cada caso formando libremente su convicción sin vinculación a lo establecido (art.273.1 en relación al 273.4 CPC).

\section{b.- Documentos Privados}

Este tipo de documentos se señalan en el artículo 278 CPC

Se aportan en original o mediante copia autenticada por el fedatario público competente, o copia simple o designará el original, donde se encuentra (art. 278 CPC).

Respecto a los libros de comerciante, se estará a la Ley sobre Normas de Contabilidad vigentes, y mediante auto y con carácter excepcional, se podrá indicar que se presente los libros o soporte in-formático, siempre que se especifiquen los asientos que deben ser examinados (art.279 CPC).

Estos documentos hacen prueba plena cuando no sean impugnados (art.280 CPC). Cuando es una dependencia del Estado y demás entidades de Derecho público tienen el deber de expedir las certificaciones y testimonios que sean solicitados por los Juzgados o Tribunales sin posibilidad de negarse a ello (art.284 CPC).

La parte puede solicitar exhibición para obtener copia a presencia del Secretario que dará fe de ser fiel y exacta reproducción del original (Art.285 CPC).

Estos documentos se presentarán en la audiencia preliminar o en la audiencia del proceso abreviado.

En cualquier momento posterior pero "antes de la audiencia en que se practique la prueba".

Excepcionalmente podrá admitirse un documento hasta el momento de comenzar el plazo para dictar sentencia, cuando la parte justifique que llegó a su conocimiento después de la audiencia en que se practicó la prueba y fuere relevante para la decisión de fondo. En este caso se oirá a la otra parte dentro del plazo de tres días.

Cuando están en un idioma distinto del español, deberán acompañarse con traducción oficial o privada por persona autorizada previamente por el Juez. En otro caso no se admitirá el documento (art. 288 del CPC)

La forma de presentación de documentos públicos extranjeros, deberán estar legalizados o aposti-llados, donde conste el carácter público y la veracidad de las firmas de las personas que los hayan autorizado, comprobándose en Honduras por los medios que se indican (art.290 del CPC).

\section{2.- Presentación y Aportación de Documentos}

Es necesario mencionar los documentos que están aportados en las diligencias preliminares (art.406 CPC).

En la demanda y contestación a la demanda (artículos 287.1 en relación con el artículo 424.8 y el 434 del CPC).

Se presentan también antes de la audiencia preliminar y de la audiencia probatoria 
cuando se trata de un hecho nuevo (art.431 CPC).

La actividad probatoria es la mera presentación (art.287 CPC).

Cuando se impugna el documento, por la parte contraria, es cuando se reproduce la actividad pro-batoria.

La impugnación de documentos públicos (art.274 P), se refiere a la existencia de una copia, certi-ficación o testimonio, que no coincide con el original, por lo que procede un cotejo entre el docu-mento aportado, y el original (art.274.1 CPC).

En cuanto a la autenticidad del mismo, se comprueba la exactitud, ocasionando costas, gastos y derechos que se abonan por la parte que exclusivamente lo impugnó (art.274.3 CPC).

La impugnación de documentos privados (art.280 CPC), cuando se impugna su autenticidad, se puede pedir el cotejo pericial de letras, firmas, huellas o proponer cualquier otro medio de prueba útil y pertinente para demostrar su autenticidad (Art.280.2 CPC).

Cuando los documentos PUBLICOS no son susceptibles de cotejo o comprobación, salvo prueba en contrario, las ejecutorias (certificación de la sentencias firmes), certificaciones (notariales, re-gístrales o administrativas), las escrituras públicas, los documentos públicos que por su índole, ca-rezcan de original o registro con el que pueda cotejarse o comprobarse (art.275 CPC).

\section{3.- Aportación de la Prueba Documental}

Se deben de presentar con la demanda o en la contestación a la demanda.

En la audiencia preliminar del proceso ordinario o en la audiencia del proceso abreviado, se pueden presentar por el ACTOR, cuando su necesidad se haya puesto de manifiesto a consecuencia de las alegaciones efectuadas por el demandado al contestar la demanda (art.287.2 CP).

Posteriormente a la demanda y contestación, pero antes de la audiencia probatoria, (art.287.3) cuando: a) Sean de fecha posterior a la demanda o a la contestación, o en su caso, a la audiencia preliminar del proceso ordinario o a la audiencia del proceso abreviado, siempre que no se hubiesen podido confeccionar ni obtener con anterioridad a dichos momentos procesales; b) Se trate de documentos, medios o instrumentos anteriores a la demanda o contestación o, en su caso, a la au-diencia preliminar del proceso ordinario o a la audiencia del proceso abreviado cuando la parte que los presente justifique no haber tenido antes conocimiento de su existencia; y c) Cuando no haya sido posible obtenerlos con anterioridad, siempre que haya hecho oportunamente la designación de archivos, protocolos o lugares, o al menos el anuncio de su presentación.

\section{C.- PRUEBA ELECTRONICA}

Es necesario que sea usada y admitida por el Juez en un proceso judicial, para lo cual 
es necesaria la utilización de tecnologías para una correcta extracción y presentación de las pruebas (legitimidad). Es necesario establecer una relación directa entre la prueba y el objeto del proceso (autenticidad).

\section{D.- PRUEBA TESTIFICAL}

Es un medio concreto de prueba, en virtud del cual se emite un testimonio por una persona ajena a las partes litigantes, que conoce los hechos objeto de debate por estar presente o por referencia.

Es una prueba de naturaleza personal (igual que la pericia), se debe de admitir, cuando se le pregunta por hechos.

Están excluidas las partes litigantes que podrán ser interrogadas, pero en la prueba correspondiente, no como testigo, pues son ajenas al proceso.

En el Código Procesal Civil para declarar la procedencia debe ser quien tenga noticia de hechos controvertidos relativos a lo que sea objeto del proceso (art.293 CPC).

\section{1.- Designación del testigo}

Es el tercero ajeno a las partes que declara sobre unos hechos presenciados o contados. Siem-pre es una persona física, que tiene condición de tercero en el proceso y que conoce el hecho cuando ocurrió.

En la propuesta que se realiza por la parte, se debe expresar su identidad indicando nombre y apellidos de cada uno, así como el cargo que ostente y cualquier otra circunstancia de identifica-ción (art.295 CPC), no se encuentra reflejado, pero sería aconsejable, sino conoce el idioma español, que se ponga de manifiesto con el fin de que el día de la audiencia probatoria, se tenga un intérprete, para que pueda efectuar la traducción al Juez.

\section{2.- Capacidad del Testigo}

2.1. Esta referida a la Inhabilidad

Los privados permanentemente de razón, (Art.409 CC son aquellas personas que no pueden dirigirse a sí mismas o administrar competentemente sus negocios, y que no se hallan bajo patria potestad)

Cuando se refiere el legislador a estar privado del uso de sentidos, se trata de que esta privado de la vista (ciego) o del oído (sordo), pero en estos casos no son causas de incapacidad jurídica, pero si pueden testificar de una determinada forma, pudiendo hacerse en otra bajo los mismos principios de publicidad, concentración y contradicción.

Según las causas establecidas en el Código Procesal Civil son testigos inhábiles, por incapacidad legal, aquellos que tienen interés directo en el pleito (art.299 CPC). 
2.2. Esta referida a la idoneidad siempre es una persona física capaz, que no está privada de razón o del uso de sentidos (art.294.2 CPC). El testigo con carácter excepcional, puede ser interrogado, cuando es menor de 14 años, pero tenga capacidad de discernimiento para conocer y declarar verazmente. (art. 294.3 CPC)

Cuando se conoce la falta de idoneidad, se debe de poner de manifiesto. (art.294.4)

2.3. Esta referida a la obligación de guardar secreto (abogados, médicos, eclesiásticos)

El incumplimiento de esta obligación conlleva indemnización derivada de la relación contractual con cliente. Ejemplo un Abogado facilita video de su cliente, es condenado.

\section{3.- Interrogatorio de Testigos}

Los testigos tienen el deber de comparecer (artículo 231 CPC), con apercibimiento de multa si no lo hacen.- Los testigos tienen derecho a que se les retribuya los gastos (art. $310 \mathrm{CPC}$ ).

3.1.- Procedimiento a seguir antes de declarar:

-Se identifica al testigo, para constancia de sus elementos personales (nombre, apellidos, domicilio y lugar de localización).

-Prestan juramento o promesa de decir verdad (art. 297 CPC), siendo informado de las penas establecidas para el delito de falso testimonio.

-Tienen el deber de declarar sobre los hechos que se les pregunta, establece la posibilidad de no declarar a aquellos testigos que tienen obligación de guardar secreto (art. 304 CPC).

-El límite de testigos es Cinco, pero cuando se hubiere escuchado al menos tres testigos con relación a un hecho controvertido, puede suprimirse el resto (art. 296.3 CPC).

-La declaración del testigo será oral y bajo juramento, excepto los menores de edad, qu se les exhortará (art. 297.2 CPC)

3.-2 Práctica e intervención de las partes:

Identificado, en presencia del Juez que preside el acto y de las partes litigantes, así como de sus defensas y representaciones, después de presta juramento o promesa, se le formulará las preguntas por la parte que ha solicitado su interrogatorio, de forma oral, con la debida claridad y precisión, sin incluir valoraciones ni calificaciones (art. 300 CPC). 
Formulada la pregunta se podrá impugnar la formulación de preguntas, por la persona que esta declarando, por la defensa de la parte contraria, o por el Juez, ya que considere que la pregunta es capciosa, sugestiva, impertinente o perjudicial para el testigo, ni aquellas que no se refieran a los conocimientos propios del testigo (art. $300.3 \mathrm{CPC}$ ).

La intervención de las partes se produce desde el primer momento, es decir desde que comparece el testigo ante el Juez, están presentes las partes, y después de ser identificado el testigo, la parte proponente podrá interrogar al testigo, y la parte contraria, podrá indicar si la pregunta es pertinente o no.

\section{E.- LA PRUEBA PERICIAL}

En el Código Procesal Civil, se le denomina pericia, cuando para valorar los hechos o circunstancias relevantes en el asunto o para adquirir certeza sobre ellos, se requieran conocimientos científicos, artísticos, técnicos, tecnológicos, prácticos u otros análogos.-

Es propuesta por la parte, que pueden optar entre aportar al proceso el dictamen de perito privado que posea los conocimientos correspondientes, o solicitar que se emita dictamen por perito oficial designado por el tribunal (artículo 315 CPC).

\section{1.- Concepto de Perito}

El Perito es la persona física que posee el título oficial que corresponda a la materia objeto del dictamen y a la naturaleza de éste. Su definición se establece en el contenido del artículo 315 del Código Procesal Civil que establece "La pericia se estimara conveniente cuando se requieran conocimientos científicos, artísticos, técnicos, tecnológicos, prácticos u otros análogos para valorar hechos relevantes en el asunto". Esta afirmación jurídica, conlleva la consecuencia de que Perito es aquel que posee los conocimientos necesarios para valorar hechos o circunstancias, permitiendo que un tercero (Juez) adquiera certeza sobre los hechos.

Si se trata de materias no comprendidas en títulos profesionales oficiales habrá de ser nombrados entre personas entendidas en aquellas materias.

Podrá asimismo solicitarse dictamen de academias, corporaciones o instituciones culturales o científicas que se ocupen del estudio de las materias correspondientes al objeto de la pericia.

También podrán emitir dictamen sobre cuestiones específicas las personas jurídicas legalmente habilitadas para ello (art. 328 CPC)

El Dictamen: Es el estudio individualizado de la materia objeto del proceso, donde se traslada los hechos y argumentaciones, sobre el objeto de debate. El informe se debe realizar por escrito y en español. 


\section{F.- RECONOCIMIENTO JUDICIAL}

Es una institución que presenta rasgos propios dentro del sistema probatorio, ya que no existía una determinación del objeto reconocible, su disponibilidad, así como la documentación de la misma.

Es la prueba que como el resto, tiende a obtener certeza respecto de las afirmaciones de hechos de las partes, con el fin de convencer al Juez.

Es el medio de prueba que se utiliza cuando para el esclarecimiento y apreciación de los hechos fuera necesario o conveniente que el tribunal examinase por sí mismo algún lugar, objeto o persona (artículo 344 CPC).

El reconocimiento judicial es la percepción por parte del Juez, de una forma directa, de los hechos que son objeto de prueba. Puede el Juez adoptar las medidas necesarias para lograr la efectividad del reconocimiento (art. 345 CPC).-

Como toda prueba, el reconocimiento judicial se solicita en la audiencia preliminar (proceso ordinario), o en la audiencia del proceso abreviado.

Se practica en la audiencia probatoria, o con anterioridad, cuando se trata de un proceso abreviado (incapacitación).

Se puede practicar en un solo acto el reconocimiento judicial y la prueba pericial sobre el mismo lugar, objeto o persona (artículo 347 CPC).

Esta prueba se documentará utilizando los medios técnicos de grabación de imagen y sonido u otros instrumentos semejantes, para dejar constancia de lo que sea objeto de reconocimiento judicial y de las manifestaciones de quienes intervengan en él, consignándose en el acta cuanto sea necesario para la identificación de las grabaciones, reproducciones o exámenes llevados a cabo, que habrá de conservarse por el tribunal (art. 349.1 CPC). Cuando no se haya podido grabar la diligencia del reconocimiento judicial se levantará por el secretario en acta detallada (art. 349.2 CPC).-

\section{VI.- VALORACION DE LA PRUEBA}

Es la operación final del procedimiento probatorio encaminada a la obtención por el juzgador de una convicción sobre la veracidad o falsedad de las afirmaciones expuestas por los litigantes.

En la doctrina el destinatario de la prueba es el Juez, es decir su convencimiento psicológico sobre la existencia o inexistencia de los datos aportados al proceso, así como aquellos datos aportados al proceso, como en aquella otra que atiende a la fijación de los datos conforme a unas normas legales.

En el sistema libre la ley deja al Juez que aplique las máximas que éste ha adquirido por su experiencia en la vida, y si se trata de una especializada se debe servir de una prueba pericial.-

Existen supuestos en donde la ley señala al juez el valor que debe atribuir a una 
determinada actividad destinada a la fijación de los hechos (prueba tasada o legal). Documento privado no impugnado.

Algunos autores, consideran que la valoración de la prueba es la operación final del procedimiento probatorio encaminada a la obtención por el juzgador de una convicción sobre la veracidad o falsedad de las afirmaciones normalmente fácticas.

La operación final del procedimiento probatorio, se produce cuando se valora la prueba practicada, y el fin de la valoración de la prueba es el convencimiento del Juez sobre la verdad o certeza de la pretensión solicitada, para lo cual la sentencia deberá de ser congruente con las pretensiones de las partes. (artículo 208 CPC)

El Juez debe de manifestar de manera clara y terminante los medios de prueba que ha tomado en consideración para llegar al resultado final (artículo 245.2 CPC).

No se deben tomar en consideración la prueba prohibida cuando vulneren las garantías procesales establecidas en la Constitución de la República, en los Convenios Internacionales relativos a derechos humanos suscritos y ratificados por Honduras y en este Código, ni cuando la obtención u origen de alguna prueba admitida ha vulnerado las garantías procesales fundamentales (artículo 237 CPC).

El fin de la valoración de la prueba consiste en el convencimiento del juzgador sobre la verdad o falsedad de determinadas afirmaciones discutidas en el proceso, esto, coincide con la finalidad de la prueba misma.

En el Código Procesal Civil, se encuentra previsto que el Tribunal excluirá en todo caso la arbitrariedad, siendo motivada de manera precisa y razonada en la sentencia, atendiendo siempre a las reglas de la sana crítica, del conocimiento y criterio humano, así como de acuerdo a las normas que rigen el razonamiento lógico, salvo que este Código u otra ley establezca una valoración legal de manera expresa e inequívoca.La valoración de los distintos medios de prueba deberá deducirse de manera clara y terminante de los fundamentos fácticos y jurídicos de la sentencia, bajo sanción de nulidad de la resolución (artículo 245 CPC).

Para cada uno de los medios establecidos en el Código Procesal Civil se establece un

\section{BIBLIOGRAFÍA}

1.- Cabanellas, Guillermo de Torres. Diccionario Enciclopédico de Derecho Usual (8 tomos, 25* edición,). Buenos Aires: Editorial Heliasta. 2003

2.- De La Oliva Santos, Andrés, y Otros, Comentarios a la Ley de Enjuiciamiento Civil, Civitas.Madrid, 2001, pág. 1967.

3.- Decreto No. 211-2006, publicado en Diario la Gaceta No. 31313, sábado 26 de mayo, 2007. Código Procesal Civil de Honduras

4.- Material, EXPLICACION INSTRUCTIVA DEL NUEVO CODIGO PROCESAL CIVIL DE HONDURAS, Cooperación Española. Marzo 2007 